\title{
Naturalismo, melodrama e mídia
}

\author{
Salete de Almeida Cara \\ Universidade de São Paulo (São Paulo, Brasil)
}

RESUMO: REFLEXÃO SOBRE O NATURALISMO NA TELEDRAMATURGIA BRASILEIRA E SUAS RELAÇÕES NA SOCIEDADE DE CONSUMO CONTEMPORÂNEA.

ABSTRACT: REFLECTION ON NATURALISM IN BRAZILIAN SOAP OPERAS AND ITS RELATIONSHIPS IN CONTEMPORARY CONSUMER SOCIETY.

PALAVRAS-CHAVE: NATURALISMO, TELEDRAMATURGIA BRASILEIRA, CONSUMO. KEYWORDS: NATURALISM, BRAZILIAN SOAP OPERA, CONSUMPTION. 
Assim, talvez. tenha chegado a hora de reafirmar, como verdade da avaliação, a lógica pervertida a que Marx se refere ironicamente em sua descrição do fetichismo da mercadoria, quando cita o conselho que Dogberry dá a Seacol em Muito barulho por nada, de Shakespeare (ato 3, cena 3), que conclui o primeiro capitulo do Capital: 'Ser um homem bonito é um dom da fortuna; mas ler e escrever vem da naturez̧a'. Hoje, em nossa época de avaliação, ser um especialista em informática ou um administrador bem-sucedido é um dom da natureza, mas ter lábios bonitos é um fato da cultura...

(Slavoj Zizek).

provocação que me fez um amigo, de olho nas relações entre literatura e mercado, pode nos levar a retomar questões que aqui apenas esboço. $\mathrm{Na}$ ocasião ele perguntou se considerar novela de televisão como representação "naturalista", tendência hoje em alta, teria algo a dizer sobre uma expectativa literária embutida na experiência de ver novelas. Até onde entendo, a etiqueta quer identificar ali relatos da vida real, embora possa até se referir à presença de paisagem e ambientes naturais numa história televisiva, como fez há pouco um jornalista ao perguntar a uma atriz se "uma novela tão naturalista quanto Araguaia"... etc, etc.

Conferir caráter realista a produções feitas sob as atuais determinações do mercado dá à qualificação uma inflexão curiosa, por certo distante da expectativa de "relatos da vida real" que acompanhou as primeiras publicações de folhetins em jornais e revistas no século XIX. Qual o critério de realismo em produções de um tempo que se dá ao luxo de não colocar em dúvida que saber avaliar é "um dom da natureza, mas ter lábios bonitos é um fato de cultura"? Está aí resumido o âmbito mercantilizado da cultura (e da própria natureza), que define o estado da questão por uma semântica própria à reprodução do aparato mercadológico-ideológico da hegemonia globalizada.

É esse aparato que sustenta a reprodução do capital que invade nosso cotidiano via satélite, com o mundo dos entretenimentos e seus efeitos especiais e, também cotidianamente, com a precariedade cada vez maior do trabalho assalariado, sobre o qual parece nem valer mais a pena pensar. Agora, quando mais do que nunca, o interesse está todo voltado para as aventuras do capital de risco (venture capital) mediadas por jovens empreendedores, administradores de portais que funcionam como vitrines de "produtos ou planos de negócios de empresas de tecnologias, de literatura e de música" (como está no Caderno Folhainvest do Jornal Folha de São Paulo de abril de 2011), ainda se produzem e se consomem novelas. 
Do que trata uma novela dita realista, além de batalhar a favor das mercadorias que invadem sem pejo a própria trama? E a que experiência elas correspondem? No meio de programas de auditório, talk shows e reality shows de baixo custo, o esquema da novela ainda tem o que dizer, com seu apelo ao mais do mesmo para quem consome (traduzindo-se em mais lucro para quem produz). Não é preciso nenhuma justificativa, a não ser viver a vida que nos cabe, para postar-se todas as noites, no mesmo horário, durante vários meses, durante vários anos, diante de uma tela que se apresenta como espelho do mundo (como se esse mundo já não estivesse em ruínas), vendo capítulos entrecortados por peças publicitárias, não apenas para vender um ou outro produto - esse resultado está aquém do interesse do aparato mercadológico-ideológico.

E talvez não haja diferença significativa se não seguirmos religiosamente todos os capítulos, mas apenas alguns para acompanhar como está sendo disposto o andamento de tramas que são, sempre, o negativo de qualquer possibilidade de movimento da vida social. Ou ainda, talvez não haja também muita diferença se a novela for não mais do que um som e uma história de fundo, dando sentido ao afazer doméstico. O que importa é preencher um tempo assustadoramente vazio com uma chance qualquer, essa mesma que as novelas oferecem ininterruptamente, uma após a outra, em blocos de repetições estruturais (um tanto de drama, um tanto de comédia), com alguma variação cosmética. Qualquer coisa que, ao fim e ao cabo, reprisa a qualidade precária da realidade, e já não exige nada mais, como resposta, além de uma participação leve e borbulhante, e de uma enfiada inconsequente de opiniões pontuais e ligeiras.

$\mathrm{Na}$ tecla do mais do mesmo está a pretensão de tratar questões sociais, como mostrou há pouco uma publicidade das novelas da Rede Globo, exibindo seu papel desbravador de assuntos tabus e preconceitos. Bem recentemente uma página da internet propôs aos internautas identificar "qual canalha da televisão se parece mais com seu ex", arrolando uma série de tipos para múltipla escolha, numa lista que trazia "o preconceituoso", "o ganancioso", "o encostado", "o oportunista”, etc, etc. Listar o preconceituoso será um avanço na direção de uma maior tolerância democrática? Como se vê, os estereótipos a que se dedicaram as narrativas mais antigas, com o intuito de reproduzir um suposto mundo social repleto de clichês morais, têm hoje novas nuances: o clichê é o novo possível na cinzenta normalidade de vidas condenadas ao não acontecimento. As pesquisas sobre o impacto das novelas no comporta- 
mento são elas mesmas sintomas, pela mera tautologia com que replicam a habitual rotina conformista de pensamento e sentimento.

Num dos capítulos mais terríveis do livro que Guy Debord escreveu em 1967 (DEBORD, 1997), o próprio tempo do consumo de imagens é, ele mesmo, mercadoria (tido, no entanto, como realidade particular e positiva de lazer e entretenimento), que realiza o imperativo da expropriação da vida e do "realmente vivido", da consciência crítica de um passado sem registro nem memória, e da consciência do próprio tempo. Enquanto tempo-mercadoria, é pulsão de morte (e não apenas ilusão) que procura compensar a necessidade da rapidez sempre maior, para uma maior eficiência de ação, com muitas horas por dia diante da televisão. Ao transporte rápido e à sopa em pó, que Debord usa como exemplos do cotidiano norte-americano, podem ser acrescentadas as engenhocas eletrônicas, de domínio geral, que conferem às comunicações interpessoais e internéticas uma imediatez que substitui relações mais efetivas de sociabilidade. ${ }^{1}$

Finalmente está sendo anunciada pela Rede SBT uma novela sobre o golpe militar de 1964, "Amor e Revolução", focada num drama de amor entre pessoas que lutavam em lados opostos. Segundo o diretor, que promete "veracidade" nas cenas, trata-se de uma novela com grande "carga dramática" (nem poderia deixar de ser). Para quem tiver paciência e interesse... Mas é bom lembrar que estaremos fazendo o jogo de iluminar um dado parcial sempre que valorizarmos o tom moralizante, que costuma dar as caras no capítulo final de cada novela, não importa o que ela tenha mastigado ao longo dos meses: o arranjo do último capítulo que os espectadores não querem perder (como qualquer consumidor que se esforça "por medo de perder alguma coisa").

Dois exemplos de desfechos que vendem gato por lebre com um pretenso teor crítico, contribuindo para a crescente despolitização da vida política: na

1. "Imobilizada no centro falsificado do movimento de seu mundo, a consciência espectadora já não conhece em sua própria vida uma passagem para sua realização e para sua morte. Quem desistiu de despender sua vida já não deve reconhecer sua morte. A publicidade dos seguros de vida apenas insinua que o indivíduo é culpado de morrer sem ter garantido a regulação do sistema depois dessa perda econômica; e a do american way of life insiste na capacidade de manter nesse encontro a maior parte das aparências da vida. Nos bombardeios publicitários restantes, é nitidamente proibido envelhecer. É como se houvesse uma tentativa de manter, em todo indivíduo, um 'capital-juventude' que, por ter sido usado de um modo medíocre, não pode pretender adquirir a realidade durável e cumulativa do capital financeiro. Essa ausência social da morte é idêntica à ausência social da vida". (DEBORD, 1992, p. 108) 
cena final, considerada antológica, de uma novela de 1988 da Rede Globo, o protagonista dá uma banana ao país e a todos que por aqui ficam, voando para outras plagas; na cena final de uma novela de 2010, da mesma rede, a sedutora e fatal heroína-vilã tem sobrevida garantida num sofisticado resort americano, para onde carrega o mesmo disfarce que usava entre milionários nacionais e, sugere-se, disposição para os mesmos golpes. No frigir dos ovos, o desagrado ou a satisfação dos espectadores, antes de passar à próxima novela (seja porque, em 2010, torciam pela regeneração da moça, seja porque, em 1988, lhes agradou a exposição da impunidade dos que levam vantagens), reforçam o esquema moral (apaziguador?) da própria mercadoria.

Nem é preciso lembrar que estamos muito distantes da luta romântica do homem contra a sociedade, presente na imaginação melodramática oitocentista européia. É de outro tipo o melodrama que sobrevive ao fim dos valores burgueses que o fez triunfar, quando a aposta na oposição do Bem contra o Mal, ou mesmo nas suas contaminações e mesclas, circulava (ao menos na Europa) num espaço de formação da opinião pública. Experiência, cujas contradições deram matéria e forma ao romance realista, que, dois séculos atrás, foi o modelo que correspondeu ao nosso legítimo desejo de ser modernos.

De modo significativo, é esse melodrama televisivo que a indústria brasileira da publicidade e entretenimento está exportando, não apenas para Portugal e Cuba, mas ainda para a China, Itália (e talvez para outros lugares, que não saberia dizer), respondendo com criatividade e eficácia à reposição da ordem do capital. Pelo menos no que aqui interessa mais de perto, somos nós que detemos hoje o know-how do modelo de narrativa televisiva, feito para exportação. Caberia ainda euforia nacionalista a pensar que, finalmente, foi possível uma inversão historicamente inédita dos lugares habituais ocupados pelos países periféricos e centrais? E se levarmos em conta que aquele antigo desejo de ser modernos promete se realizar com nossa inserção no mercado mundial, pela opção de biocombustíveis e demanda internacional por commodities?

Nesse cenário, é coisa de ave de mau agouro sugerir quaisquer entraves ao nosso processo de internacionalização - tais como regulação do mercado, preços voláteis dependentes do capital especulativo - ou referir-se, desastradamente, a desemprego estrutural, reprodução das desigualdades e aumento da fome causado pela própria especulação. Soaria como velharia inútil repisar a distância entre trabalhador e o produto que ele produz, ou entre especta- 
dor e o produto da cultura de massa que ele consome, diante do que parece ser óbvio como um dom da natureza, a saber, a independência da esfera do consumo, onde os sujeitos circulariam em liberdade de pensamento e ação. No entanto, o que parece coisa antiga, a suposta velharia de mau agouro é justamente o estatuto realista da contemporaneidade, pelo qual os conteúdos das novelas não podem mesmo se interessar. ${ }^{2}$

Chega a ser falta de modos insistir, com saudosismo, naquele antigo desejo de conhecimento que sempre foi correlato ao desejo de ficção. Afinal, diriam muitos, a novela não é hoje apenas mania nacional, e sua produção, com novo padrão técnico e esquema melodramático renovado, nos deu a chance de ingressar pela porta da frente na lógica contemporânea do entretenimento. Renovação que, no entanto, confere papel estratégico ao que parece mescla de Hollywood, folhetim e crônica. Ismail Xavier chamou a atenção para a incorporação de recursos formais e do senso "da vida como ela é" de Nelson Rodrigues em novelas da Globo, dando uma versão amena da visão amargurada e pessimista do dramaturgo.

Desse modo, a novela cumpriria a demanda pedagógica própria da televisão, no "trato da decadência do patriarcado e da crise dos códigos da moral religiosa na sociedade brasileira". Puxando um fio polêmico, cabe, no entanto, ao próprio Nelson Rodrigues lugar de destaque na "tragichanchada nacional" (a expressão é de Vinicius Dantas) como fenômeno de mercado, que inclui a "releitura exultante" que Arnaldo Jabor fez do dramaturgo, ao encenar, sem crítica nem distanciamento, o desastre da nossa formação social. Ou, como diz Ismail Xavier, um certo estilo de dominação enraizado na formação social brasileira. ${ }^{3}$

O fato é que o padrão da novela de televisão cai como uma luva na aparente democratização de uma sociabilidade de formação frágil, que nunca chegou a constituir propriamente sua esfera pública, e onde a modernização dita burguesa dependeu desde sempre, e até hoje, da manutenção do atraso. Arremedo do re-

2. Quando Karl Marx falou em "compulsão ao trabalho alienado" ele já se referia ao modo como o próprio sistema de produção prevê a reprodução da hegemonia na vida cotidiana, sugando inclusive o voo da imaginação.

3. Segundo Vinicius Dantas, na orelha do livro de Ismail Xavier, tratando da releitura de Jabor, "o moralismo de esquerda projetou na família e no patriarcalismo a própria ditadura militar, encenando rituais de agressão e transgressão, conflitos de geração, demolições da figura do pai...”. Cf. XAVIER, 2003. 
gistro melodramático que, dois séculos atrás, atendia ao novo mercado popular de consumidores, a novela expõe sua funda identificação com uma lógica de acumulação e espoliação social que tem, como pressuposto, a condição de zero de discussão política, zero de participação pública e preenchimento passivo da vida cotidiana individual e coletiva com experiências vicárias (sendo o desinteresse quase geral pelos desafios do presente uma prova de força da ordem mundial).

Mas, mesmo assim, ou por isso mesmo, o impasse se mantém: como insistir na contramão do que parece ser democratização do entretenimento (que, afinal, atinge todos os níveis sociais), impulso positivo a favor da variedade de públicos e propósito de inclusão de minorias que aparecem como personagens nas novelas? Como tratar do que parece ser tão fora de moda, a saber, a crítica ao mercado da indústria cultural, posição acusada frequentemente de superioridade elitista e mesmo conservadora?

De fato, é difícil expor questões dessa natureza como se fossem problemas, já que a ampliação do consumo é, definitivamente, constitutiva da direção que toma um progresso do qual parecemos finalmente participar, em condições que não a de periféricos, e no qual estamos, cada um de nós, mergulhados em cada projeto e em cada escolha que acene com a possibilidade de melhorar a vida (e quem não merece melhorar de vida?). Diante das forças de sustentação da hegemonia global, o desafio é de onde exercer uma ironia capaz de propor a problematização da totalidade, de onde imaginar outra ordem para o mundo, sem perder de vista a complexidade e os modos de inserção de todos nós no mesmo processo hegemônico.

Por isso, é preciso perguntar que lugar ocupa aquele que se torna sujeito apenas como consumidor, enquanto as forças do mundo do trabalho continuam em refluxo. Daí o interesse da sugestão formulada em perspectiva marxista por Slavoj Zizek: considerando a encruzilhada irredutível e complementar entre universo da produção e do consumo na criação do valor da mercadoria (no consumo se dá efetivamente a exploração daquele que já foi pago pela sua força de trabalho), ele propõe a consideração desses universos como duas frentes irreconciliáveis, mas complementares.

O salto emancipatório da consciência estaria na exigência de consumo para todos nos termos dos valores do próprio mercado? Para responder e reverter esse foco, o pulo do gato estaria em não conferir toda a responsabilidade pelo caráter ilusório do processo mercantil às esferas da troca e do consumo, não de- 
legar inteiramente ao aparato mercadológico-ideológico da mídia e da publicidade o papel de moldar mentalidades, condenando irremediavelmente ao papel de vítimas, sob a alegação cínica da democratização do entretenimento, justamente aqueles que mais perdem (uma vitimização ela mesma melodramática).

Nos anos de 1960, estudando o funcionamento da televisão como motor de socialização e adaptação da psique individual, no ritmo dos interesses econômicos, Theodor Adorno não perdeu de vista o duplo papel do trabalhador enquanto consumidor (como está em Marx), opondo-se à visão moralista segundo a qual a indústria cultural moldaria uma passividade constitutiva de todo ser humano, responsabilizado pelo nível degradado do que lhe era oferecido. E mostrava que, sob a aparência de sociabilidade, solidariedade e interesses dos próprios consumidores, a indústria cultural completava o processo de reificação inscrito no caráter especulativo da própria produção. O processo hoje se agrava com a reprodução combinada, mas irredutível nos termos de Zizek, de produção (com mão de obra barata) e consumo (onde se realiza também a exploração e o lucro).

A dupla observação (enquanto produtor e enquanto consumidor) pode ser o lugar de onde levar a sério e problematizar o que tem a dizer a etiqueta "vida real" que acompanha o consumo de um melodrama televisivo. De saída, seu sentido se desdobra, se dilui e ganha corpo no próprio procedimento de etiquetagem que, em alta com o crescente enfraquecimento do senso das diferenças históricas que marca nosso tempo, compromete seriamente a própria imaginação. E, no limite, é gesto dócil e cordato a uma forma e conteúdos regressivos, que fazem passar com sucesso, como inofensiva normalidade, o tratamento conferido à vida cotidiana, à vida familiar e às relações de sociabilidade, figurando interesse por problemas de uma sociedade - no caso, a brasileira - sobre a qual pouco se sabe e pouco se discute (mas, pelo andar da carruagem alcança, via novelas, generalidade suficiente para comover em plano global).

\section{Referências bibliográficas}

DEBORD, Guy. A sociedade do espetáculo: comentários sobre a sociedade do espetáculo. $4^{a}$ ed. Rio de Janeiro: Contraponto, 1992.

XAVIER, Ismail. O olhar e a cena. São Paulo: Cosac \& Naify, 2003.

Recebido em 03 de maio e aprovado em 18 de maio de 2011. 